\title{
Evidence of a relationship between adult attachment variables and appraisals of chronic pain
}

\author{
Pamela J Meredith BA BSc, Jenny Strong PhD MOccThy, Judith A Feeney PhD BA
}

\begin{abstract}
PJ Meredith, J Strong, JA Feeney. Evidence of a relationship between adult attachment variables and appraisals of chronic pain. Pain Res Manage 2005;10(4):191-200.
\end{abstract}

OBJECTIVE: Although threat and challenge appraisals of pain have been linked to both the acute and laboratory-induced pain experience, these appraisals have not yet been explored in relation to chronic pain. In addition, although attachment theory has been separately linked to the chronic pain experience and to responses to perceived threat, it has not been explored in the context of threat and challenge appraisals of chronic pain. The present paper addresses these two main goals.

METHODS: A sample of 141 participants reporting noncancer pain longer than two months in duration completed a battery of assessments before commencing treatment in one of two multidisciplinary rehabilitation programs.

RESULTS: Analysis of the pain appraisal inventory produced two factors (threat and challenge), replicating earlier findings. Reliability coefficients for the two extracted scales were 0.87 and 0.86 , respectively. Links between the two pain appraisal scales and adult attachment variables proved to be significant. In particular, comfort with closeness was strongly related to challenge appraisal, while anxiety over relationships was strongly associated with threat appraisal. As expected, both appraisals and attachment variables were also related to catastrophizing and emotional distress.

CONCLUSIONS: Results support use of the pain appraisal inventory as an evaluation tool for those with chronic pain. Findings further suggest a substantial association between adult attachment and pain appraisal, supporting the need for more in-depth analysis and consideration of implications for treatment.

Key Words: Attachment; Challenge appraisal; Chronic pain; Threat appraisal

A ttachment theory, in general (1), and adult attachment theory, in particular $(2,3)$, have been gaining theoretical and empirical credibility as a framework for understanding chronic pain. Adult attachment variables have increasingly been linked to the experience and presentation of those with chronic pain, particularly to coping strategies, pain intensity and disability, adjustment to pain, distress, depression, catastrophizing and use of health care services (4-7).

According to attachment theory, appraisals of threat activate the attachment system and mobilize attachment behaviours designed to increase proximity to an attachment figure (8). Pain is recognized as having considerable 'threat value' (9), and the role of threat and challenge appraisals in pain has been demonstrated (10-13). Nevertheless, the relationship between

\section{Existence d'un lien entre les variables de l'attachement chez l'adulte et l'évaluation de la douleur chronique}

BUT : Même si un lien a déjà été établi entre l'appréciation de la menace, l'appréciation des difficultés et l'expérience de la douleur aiguë et de la douleur provoquée en laboratoire, ces deux types d'appréciation n'ont jamais été étudiés en rapport avec la douleur chronique. De plus, bien que la théorie de l'attachement ait été liée isolément à l'expérience de la douleur chronique et aux réactions à la perception de la menace, elle n'a pas été étudiée dans le contexte de l'appréciation de la menace et de l'appréciation des difficultés liées à la douleur chronique. Le présent article porte sur ces deux aspects.

MÉTHODE : Un échantillon de 141 participants qui se plaignaient de douleur non cancéreuse depuis plus de deux mois ont rempli une série d'évaluations avant de commencer leur traitement dans un des deux programmes pluridisciplinaires de réadaptation.

RÉSULTATS : L'analyse des différentes méthodes d'évaluation de la douleur a permis de dégager deux facteurs (la menace et les difficultés), confirmant ainsi des résultats antérieurs. Le coefficient de fidélité des deux échelles dégagées s'établissait à 0,87 et à 0,86 respectivement. Les liens entre les deux échelles d'évaluation de la douleur et les variables de l'attachement chez l'adulte se sont avérés importants; plus particulièrement, le confort était fortement lié à l'appréciation des difficultés, et l'anxiété, à l'appréciation de la menace. Comme prévu, les deux types d'appréciation et les variables de l'attachement étaient également liés à l'anticipation de catastrophes et au trouble émotionnel. CONCLUSIONS : Les résultats confirment la pertinence des méthodes d'appréciation de la douleur comme outil d'évaluation chez les personnes affligées de douleur chronique. Les observations semblent également indiquer l'existence d'un lien important entre l'attachement chez l'adulte et l'évaluation de la douleur, d'où la nécessité de poursuivre les recherches et d'en examiner la portée sur le traitement.

attachment security and such pain appraisals has not been explored. A clearer understanding of the inter-relationship among these variables will assist in our conceptualization of chronic pain, and may have important implications for treatment.

\section{ADULT ATTACHMENT THEORY}

Individual differences in adult attachment are conceptualized as reflecting emotional, cognitive and behavioural schemas, or internal working models, developed gradually by each individual from the time of birth as an adaptive response to the external environment (14-16). Based on the stability, consistency and appropriateness of early social experiences, adults may develop a predominantly secure attachment pattern or one of 


\begin{tabular}{|ccc|c|}
\hline \multirow{2}{*}{$\begin{array}{c}\text { Model of } \\
\text { other }\end{array}$} & Positive & Positive & Model of Self \\
\cline { 3 - 4 } & Negative & Secure & Negative \\
\cline { 3 - 4 } & & Dismissing & Fearful \\
\cline { 3 - 4 } & & & \\
\hline
\end{tabular}

Figure 1) Conceptualization of attachment styles. Reproduced with permission from reference 18

three insecure patterns. The three insecure patterns, known as preoccupied, dismissing and fearful (17-18), vary according to one's perception of others as being available or unavailable, and of the self as being worthy or unworthy of love and attention (Figure 1).

Attachment has also been conceptualized as a dimensional, as opposed to a categorical, construct. Two dimensions have consistently been identified: 'comfort with closeness' (known as 'comfort' or, at the other end of the dimension, 'avoidance') and 'anxiety over relationships' (or 'anxiety') (19). Although continuous methods of assessing attachment style (afforded by dimensional measures) have been shown to provide a more accurate picture than that available using the four discrete categories (20), categories continue to be frequently used in research for their ease of administration and interpretation.

The utility of attachment theory as an organizing construct for interpersonal and noninterpersonal appraisals has been presented by Torquati and Vazsonyi (21). These authors noted that events are interpreted through the filter of internal working models. The perception of threat further activates these working models, which then impact on affective and coping responses, and further influence appraisals. According to Cole-Detke and Kobak (22), it is the security of attachment working models that predominantly affects how individuals process distressing events, and the affective and coping responses employed. Indeed, Alexander et al (23) found that secure attachment was associated with positive appraisal of the transition to parenthood, and hence was viewed as a core protective factor in the context of stress; conversely, insecure attachment was associated with negative appraisals and viewed as a core risk factor.

These links between attachment security and appraisals suggest that the appraisal of pain warrants consideration from the perspective of adult attachment theory. Threat and challenge appraisal factors have been considered in relation to pain and attachment separately, and this body of literature is briefly summarized below. However, research integrating cognitive appraisals of pain and attachment security has not previously been conducted.

\section{THREAT AND CHALLENGE APPRAISAL OF PAIN} Cognitive appraisal of pain is considered critical to the pain experience $(10-13,24-27)$, and reductions in negative cognitions have been demonstrated to impact positively on multidisciplinary treatment outcomes (28). Lazarus and colleagues (29-31) have argued that appraisal should be defined in terms of harm-loss (for past events), threat or challenge. Consistent with this assertion, Unruh and Ritchie (12) have defined appraisal of pain in terms of perceived threat or challenge. A threat appraisal is a negative interpretation of pain, and is associated with negative emotions such as depression and anxiety. A challenge appraisal, on the other hand, is a more positive appraisal and is suggestive of an inherent resilience.
Individuals making a challenge appraisal believe they will cope with (and possibly even gain from) the painful experience. Tomaka and colleagues $(32,33)$ have linked threat and challenge appraisals with physiological reactivity, citing consequences for energy mobilization and effort. Indeed, evidence using the pain appraisal inventory (PAI) suggests that the appraisal of pain as threatening is associated with increased pain intensity, disability, being emotionally upset (12), catastrophizing and health care use (11) and pain responsivity (ie, tolerance and perception of intensity [10]). Pain challenge appraisals, on the other hand, have been associated with positive self-statements (11). Although the PAI has been explored for use with acute pain (12) and laboratory-induced pain (10), it has not yet been used with a chronic pain sample.

\section{ATTACHMENT AND APPRAISAL OF PAIN}

According to attachment theory $(14,15)$, appraisal of pain (and associated events including changes to work, health and social roles) as stressors activates the attachment system, thus eliciting a complex of cognitions, emotions and attachment behaviours. As noted, however, the extent of the initial activation depends on the security of the individual's internal working models. Bartholomew et al (8) have commented on the varying thresholds of activation held by individuals with different attachment styles, noting that the preoccupied and fearful groups (who have negative models of self) are more likely to perceive events as threatening, and to respond to lower levels of stress with considerable anxiety and distress. This may be more problematic for fearful than for preoccupied individuals, because while both desire relationships with others and depend excessively on others for perceptions of self-worth, fearful individuals are also concerned with fears of rejection. The secure and dismissing groups, on the other hand, are described as more confident in their ability to cope effectively with stress, and as having a relatively high threshold of attachment activation. Indeed, the dismissing group is seen as likely to avoid activation of the attachment system and the desire for intimate contact by defensively excluding awareness of distress.

Evidence suggests that securely attached individuals are more likely to appraise events realistically and respond appropriately to stressors such as pain $(6,34-37)$, thus obtaining appropriate and timely intervention. Preoccupied (anxiously attached) individuals are likely to amplify pain-related distress cues, exaggerating the extent of pain and associated difficulties, and demonstrate extensive pain behaviour $(16,38,39)$. In contrast, dismissing (avoidant) individuals are likely to ignore pain signals or appraise them as posing little threat. These insecure strategies are broadly known as hyperactivating (anxious) and deactivating (avoidant).

For fearfully attached individuals, perceptions of threat may result in indiscriminate, and usually ineffective, use of either hyperactivating or deactivating responses. Like the preoccupied group, fearful individuals report high levels of subjective distress; however, they are more like the dismissing group in their tendency to withdraw and hide their distress and to have fewer supports. Both hyperactivating and deactivating approaches are deemed maladaptive in the long term, because they may result in failure to gain support, failure to address the source of distress or a prolonged distress reaction. Mikulincer and Florian (6), for example, have cited unpublished data indicating that insecurely attached patients with chronic pain describe their pain as more threatening and 
themselves as less capable of dealing with it than securely attached patients.

\section{THE ROLE OF CATASTROPHIZING}

Strong links have been reported in pain samples between catastrophizing and both attachment anxiety (4) and threat appraisal $(12,13)$. Indeed, Unruh et al (13) noted that it is unlikely that catastrophizing will occur without some measure of threat appraisal. These authors suggested that high levels of catastrophizing presuppose a high perception of threat, but noted that this relationship would not necessarily hold in reverse. In contrast, the cognitive theory of stress and coping suggests that threat appraisal (a primary appraisal) would predict catastrophizing (a secondary appraisal) (10).

This dilemma reflects the still controversial nature of catastrophizing, which has variably been described as a cognitive construct (24), an emotion-focused pain coping strategy $(40,41)$ or an emotional/behavioural/cognitive complex $(42,43)$. Sullivan et al $(44)$ suggested that, for those in chronic pain, catastrophizing may be aimed at eliciting support, care-taking and sympathy from others. Likewise, Ciechanowski et al (4) suggested that increased expressions of distress associated with catastrophizing might obtain solicitous support. Bowlby (14) defined attachment behaviour as "seeking and maintaining proximity to another individual". He observed that, in adulthood, it is readily elicited in times of "sickness and calamity...sudden danger or disaster", when proximity to a known and trusted other is naturally sought (14). Based on these definitions, we suggest that catastrophizing may be best conceptualized as an attachment behaviour. Further, based on the hyperactivating tendencies of those with anxious attachment patterns, it is more likely that individuals high in relationship anxiety would engage in catastrophizing (4).

\section{RESEARCH QUESTIONS AND HYPOTHESES}

A preliminary objective of the present study was to determine the reliability of the PAI for use with individuals with chronic pain. It was predicted that two scales, consistent with those detected in an acute pain sample, would be identified in the chronic pain population, and that reliability coefficients would be adequate for use with the present sample.

The main objective of the present study was to explore the links between threat and challenge appraisals of pain and adult attachment variables in a chronic pain sample. It was proposed that individuals reporting insecure-anxious attachment would appraise pain as more threatening than would insecureavoidant or secure counterparts. It was also expected that those reporting secure attachment would appraise their pain as more challenging and less threatening than those reporting insecure attachment. Further, because previous research has linked both threat appraisal and insecure attachment independently with increased pain intensity, disability, emotional distress and catastrophizing, these variables were also measured. Based on the developmental primacy of attachment schemas, it is expected that appraisals of pain would mediate relationships between attachment and each of these variables.

\section{METHODS}

\section{Participants}

The present study was conducted as part of a larger longitudinal study. All clients attending two private metropolitan chronic pain rehabilitation centres, Gregory Terrace Rehabilitation and PainLogic (Brisbane, Australia), over a 14-month period were invited to participate. A total of 141 participants agreed to participate in this stage of the study, 88 from Gregory Terrace Rehabilitation and 53 from PainLogic. Although no record was made of clients not agreeing to participate, 325 clients were registered at the clinics during this period. The response rate was approximately $44 \%$. All participants were volunteers who had chronic pain (between two months and 34 years in duration) of noncancer origin. They had been in pain for an average of three years and nine months ( $\mathrm{SD}=7.07$ months), and were between 18 and 82 years of age (mean age $38.89 \pm 12.31$ years). Sex, demographic and pain-related details are shown in Table 1.

\section{Procedure}

Ethical clearance for this project was obtained from The University of Queensland's Behavioural and Social Science Ethical Review Committee, Brisbane, Australia. The primary investigator attended each clinic on the first day of each program to personally invite participation in the research, distribute information sheets and consent forms, and collect completed questionnaires.

\section{Measures}

Relevant measures and information collected by the pain rehabilitation centres are described below.

Demographic information: Data regarding age, sex, marital status, education, employment status, litigation status, workers' compensation status, duration of pain, location of pain and country of origin.

Oswestry disability index (45-47): This index is one of the most frequently used outcome measures of function in those with chronic back pain. In over 20 years, many papers have supported its validity and reliability (46). The index asks clients to select a statement that best describes the functional impact of pain in 10 areas: pain relief, personal care, lifting, walking, sitting, standing, sleeping, sex life, social life and travelling. The alpha reliability for this measure for the present sample was 0.80 .

Visual analogue scale (48): This scale is a common instrument for measuring pain intensity. It consists of a series of four $10 \mathrm{~cm}$ horizontal lines, anchored at each end and labelled 0 'no pain' at one end and 10 'pain as bad as it can be' at the other. Patients are asked to make a mark on each respective line at the point corresponding to their pain now, their highest level of pain, their lowest level of pain and their average pain, over the past week. The length of these lines is then measured in centimetres from the no pain end, and the final result divided by four as an indicator of average pain intensity $(49,50)$.

Depression anxiety stress scales 21: The depression anxiety stress scales 21 (DASS 21) $(51,52)$ is a brief version of the 42 -item DASS and consists of 21 questions exploring negative emotions experienced over the past week. Questions are scored on a fourpoint scale ( 0 'did not apply to me at all' to 3 'applied to me very much or most of the time'). Scores for the depression, anxiety and stress scales are obtained by summing the relevant seven items. Sample items for each of the scales include 'I tended to overreact to situations' (stress), 'I felt scared without any good reason' (anxiety) and 'I couldn't seem to experience any positive feeling at all' (depression). Previous studies $(51,53)$ support the reliability, convergent and discriminant validity of the original 42-item scale. Similarly, findings from application of the DASS to a clinical sample demonstrate excellent internal consistency, temporal stability, convergent and discriminant validity, and 
TABLE 1

Descriptive data for demographic variables

\begin{tabular}{|c|c|}
\hline Variable $(n=141)$ & Frequency, $\mathbf{n}(\%)$ \\
\hline \multicolumn{2}{|l|}{ Sex } \\
\hline Men & $83(58.9)$ \\
\hline Women & $58(41.1)$ \\
\hline \multicolumn{2}{|l|}{ Marital status } \\
\hline Married/cohabitating & $95(67.4)$ \\
\hline Divorced & $14(9.9)$ \\
\hline Separated & $4(2.8)$ \\
\hline Never married & $26(18.4)$ \\
\hline Widowed & $2(1.4)$ \\
\hline \multicolumn{2}{|l|}{ Education } \\
\hline Did not complete school & $19(13.5)$ \\
\hline Junior & $42(29.8)$ \\
\hline Senior (HSC) & $30(21.3)$ \\
\hline TAFE/apprenticeship & $35(24.8)$ \\
\hline Graduate & $12(8.5)$ \\
\hline Missing & $3(2.1)$ \\
\hline \multicolumn{2}{|l|}{ Country of origin } \\
\hline Australia & $121(85.6)$ \\
\hline Other & $20(14.2)$ \\
\hline Austria & $1(0.7)$ \\
\hline Bosnia & $1(0.7)$ \\
\hline Italy & $1(0.7)$ \\
\hline New Zealand & $5(3.5)$ \\
\hline Philippines & $3(2.1)$ \\
\hline Scotland & $1(0.7)$ \\
\hline South Africa & $1(0.7)$ \\
\hline United Kingdom & $6(4.2)$ \\
\hline Vietnam & $1(0.7)$ \\
\hline \multicolumn{2}{|l|}{ Location of pain } \\
\hline Total body (more than two locations) & $43(30.5)$ \\
\hline Lower back and limbs & $78(55.3)$ \\
\hline Upper back and limbs & $13(9.2)$ \\
\hline Other (head, viscera) & $7(5)$ \\
\hline \multicolumn{2}{|l|}{ Cause of pain } \\
\hline Work accident or injury & $95(67.4)$ \\
\hline Motor vehicle accident & $17(12.1)$ \\
\hline Unknown & $13(9.2)$ \\
\hline Other (home accident, illness, injury, fibromyalgia) & $16(11.3)$ \\
\hline Missing & $2(1.4)$ \\
\hline \multicolumn{2}{|l|}{ Litigation status } \\
\hline Yes & $26(18.4)$ \\
\hline No & $113(80.1)$ \\
\hline Missing & $2(1.4)$ \\
\hline \multicolumn{2}{|l|}{ Workers' compensation status } \\
\hline Yes & $96(68.1)$ \\
\hline No & $45(31.9)$ \\
\hline \multicolumn{2}{|l|}{ Current employment } \\
\hline Employed full time & $28(19.9)$ \\
\hline Employed part time & $7(5.0)$ \\
\hline Unemployed & $34(24.1)$ \\
\hline Retired & $10(7.1)$ \\
\hline Sick leave & $60(42.6)$ \\
\hline Missing & $2(1.4)$ \\
\hline
\end{tabular}

HSC High school certificate; TAFE Technical and further education

consistent factor structure (54). Factor analyses have also confirmed the three-scale structure of the 21-item DASS (55). Alpha reliabilities for the present study were 0.90 for stress, 0.86 for anxiety and 0.92 for depression.
In addition, the research questionnaire designed for the present study included the measures described below.

The relationship questionnaire: The relationship questionnaire (RQ) (18) is a style-based approach for measurement of attachment (19), and consists of both categorical and continuous selfreports. The categorical measure is a forced-choice measure in which the participant selects one of four paragraphs describing secure, preoccupied, fearful-avoidant or dismissive-avoidant attachment. The continuous measure asks participants to rate on a seven-point scale ( 1 'not like me at all' to 7 'very much like me') the extent to which they resemble each of the four attachment styles. The RQ is a widely used measure of attachment showing adequate predictive validity and test-retest reliability $(56,57)$.

Attachment style questionnaire: The attachment style questionnaire (ASQ) (19) is a 40-item self-report measure of adult attachment style. Items are rated on a six-point scale (1 'totally disagree' to 6 'totally agree'). Two major attachment dimensions, degree of comfort with closeness (avoidance or comfort) and anxiety over relationships (anxiety), are consistently derived from this measure $(19,23,58)$. In a recent comparison of a range of attachment style measures, the ASQ was found to be one of the two most discriminating (59). In the present study, alpha coefficients for the two dimensions were 0.82 ('comfort') and 0.92 ('anxiety'), with scales consisting of 10 and 23 items, respectively. An example of a comfort item is 'I feel confident that people will be there for me when I need them', while an example of an anxiety item is 'I worry about people getting too close'.

PAI: This 16-item self-report inventory (12) measures cognitive appraisals of pain. Two scales measuring perceived threat and challenge each consist of eight items, and items are scored on a sixpoint scale ( 1 'strongly disagree' to 6 'strongly agree'). Threat and challenge scores are represented as mean scores. Sample items include 'I feel controlled by the pain' (threat) and 'I think the pain is a chance to prove myself' (challenge). Content validity, internal consistency and concurrent criterion validity have been reported $(12,13)$. Factor analysis confirmed the presence of two scales, identical to the two identified by Unruh and Ritchie (12), which were, therefore, labelled 'threat' and 'challenge'. Alpha reliabilities for the present study were 0.87 for threat and 0.86 for challenge.

Coping strategies questionnaire - catastrophizing subscale: This questionnaire (60) is a six-item self-report measure of pain catastrophizing, which has been used extensively in pain research. All items are rated on a seven-point scale ( 0 'never do that' to 6 'always do that'). A sample item is 'it is terrible and I feel it is never going to get any better'. In the present sample, the alpha coefficient for this scale was 0.87 .

\section{Statistical analysis}

All data were analyzed using the statistical package SPSS 11.0 (SPSS Inc, USA). The range of analyses used in these investigations is detailed in the Results section. Where multiple regression was employed, stepping method criteria were minimized to 0.01 on entry and 0.02 on removal, to decrease the risk of making a type I error. Missing data on any variable resulted in failure of the variable to be calculated for that participant, and hence these data were lost from analysis. This loss resulted in a smaller sample population for some calculations. Descriptive statistics, including frequency distributions, were conducted (Tables 1 and 2) and used for the purposes of data checking. No outliers were detected. Because there were only two widowed participants, these were removed from analyses of marital status. 
Five skewed variables were identified, with four scales positively skewed (pain chronicity, RQ preoccupied, DASS anxiety and DASS depression) and one scale negatively skewed (ASQ comfort). These variables were transformed using logarithmic transformations for the positively skewed scales and reflected logarithmic transformations for the negatively skewed scale. Analyses using the transformed variables did not vary substantially from the nontransformed variables, hence the nontransformed results are reported.

\section{Demographic details}

\section{RESULTS}

The relationships between each of the experimental variables and 10 demographic variables were explored to establish whether these variables should be covaried in subsequent analyses. As a result of these preliminary analyses, eight demographic variables (age, sex, marital status, employment status, litigation status, workers' compensation status, pain duration and location of pain) were block entered as covariates in multivariate regression analyses. In only one of these analyses were any demographic variables significant. To retain maximum degrees of freedom, other regression equations are reported without covariates.

\section{Descriptive statistics}

Attachment: Using the categorical measure of the RQ $(n=141), 47(33.3 \%)$ participants reported a secure attachment style, $27(19.1 \%)$ reported a fearful attachment style, $15(10.6 \%)$ were preoccupied and 31 (22\%) indicated a dismissing attachment style. These findings suggest lower levels of attachment security than might be expected in the general population. Descriptive data for the continuous $R Q$ measures and the ASQ are provided in Table 2. Inspection of these data suggests slightly higher levels of attachment security relative to each of the insecure styles, and somewhat more attachment comfort than anxiety over relationships.

Pain appraisal: Descriptive data for the two PAI scales are presented in Table 2. The mean challenge appraisal score (2.92) was somewhat lower than the mean threat appraisal score (4.11), but both scores were higher than those reported for an acute sample (challenge 1.9 and threat 3.1 [12]). To permit further comparison with data in the acute sample used in Unruh and Ritchie's (12) study, it was calculated that $83.7 \%$ of the participants reported a threat appraisal greater than three (reflecting agreement that pain is threatening), while $45.7 \%$ of participants reported a challenge appraisal greater than three. These numbers were considerably larger than those of the acute pain sample (51\% for threat appraisal and 14\% for challenge appraisal).

\section{Correlations}

Correlations were computed to explore broad relationships among the experimental variables. Results are summarized in Table 3. Consistent with theoretical predictions, several strong correlational relationships emerged. ASQ anxiety was positively correlated with threat appraisal, RQ fearful, RQ preoccupied, catastrophizing and the three DASS emotional distress variables, and negatively correlated with ASQ comfort and RQ secure attachment. On the other hand, ASQ comfort was positively correlated with challenge appraisal and RQ secure attachment, and negatively with ASQ anxiety, RQ fearful,
TABLE 2

Descriptive statistics for continuous variables

\begin{tabular}{lccccc}
\hline Variable & $\mathbf{n}$ & Mean & SD & Minimum & Maximum \\
\hline Catastrophizing & 140 & 15.35 & 9.24 & 0 & 36 \\
Threat appraisal & 141 & 4.11 & 1.10 & 1.38 & 6 \\
Challenge appraisal & 137 & 2.92 & 1.13 & 1 & 5.63 \\
RQ secure & 139 & 4 & 2.14 & 1 & 7 \\
RQ fearful & 136 & 3.38 & 2.09 & 1 & 7 \\
RQ preoccupied & 137 & 2.71 & 1.85 & 1 & 7 \\
RQ dismissing & 135 & 3.86 & 1.94 & 1 & 7 \\
ASQ anxiety & 121 & 2.9 & 0.9 & 1 & 5.48 \\
ASQ comfort & 136 & 4.1 & 0.83 & 1.1 & 6 \\
DASS stress & 136 & 18.88 & 11.59 & 0 & 42 \\
DASS anxiety & 137 & 11.05 & 10.15 & 0 & 42 \\
DASS depression & 139 & 16.33 & 11.89 & 0 & 42 \\
Oswestry disability & 104 & 41.73 & 13.48 & 12 & 78 \\
Average pain intensity & 121 & 5.37 & 1.78 & 1.75 & 10 \\
\hline
\end{tabular}

ASQ Attachment style questionnaire; DASS Depression anxiety stress scale; $R Q$ Relationship questionnaire

DASS anxiety and DASS depression. Interestingly, given the strength of other associations, average pain intensity and Oswestry disability were not correlated with any of the attachment variables.

Linking attachment and pain appraisal

Threat appraisal: ANOVA with the RQ categorical measure as the independent variable revealed a significant association with threat appraisal $(\mathrm{F}[3,116]=3.02, \mathrm{P}=0.03)$. A post hoc Bonferroni test identified the RQ-secure group as reporting a marginally less threatening interpretation of the pain than that in the RQ-fearful or RQ-dismissing groups $(\mathrm{P}=0.08$ and $\mathrm{P}=0.09$, respectively, Table 4). Multiple regression, incorporating each of the variables significantly correlated with threat (DASS stress, DASS depression, DASS anxiety, Oswestry disability index, ASQ anxiety, average pain intensity and catastrophizing) as independent variables, and threat appraisal as the dependent variable, was significant $(F[7,65]=9.49$, $\mathrm{P}<0.001$ ), accounting for $45.2 \%$ of the variance in threat. Catastrophizing emerged as the only unique predictor of threat appraisal $(\mathrm{B}=0.6, \mathrm{t}=4.32, \mathrm{P}<0.001)$.

Challenge: ANOVA with the RQ categorical measure as the independent variable was unrelated to challenge appraisal. Challenge was also unrelated to continuous $R Q$ variables and ASQ anxiety. When the two variables correlated with challenge appraisal (DASS depression and ASQ comfort), along with the eight covariates, were entered as independent variables into a multiple regression equation predicting challenge appraisal, a significant result was obtained $(\mathrm{F}[10,117]=3.64, \mathrm{P}<0.001)$. The predictor variables explained $17.2 \%$ of the variance in challenge appraisal. ASQ comfort contributed most strongly to the prediction $(B=0.29, t=3.26, P=0.001)$. Workers' compensation status and age also emerged as significant predictors $(B=0.3, t=2.87$, $\mathrm{P}=0.005$ and $\mathrm{B}=-0.2, \mathrm{t}=-2.19, \mathrm{P}=0.03$, respectively), with those not receiving compensation and younger participants reporting higher levels of challenge appraisal.

\section{Categorical RQ measure}

Four additional ANOVAs were conducted with RQ (categorical) attachment as the independent variable. The dependent 
TABLE 3

Correlations among variables

\begin{tabular}{|c|c|c|c|c|c|c|c|c|c|c|c|c|c|}
\hline & API & $\begin{array}{c}\text { Catastro- } \\
\text { phizing }\end{array}$ & $\begin{array}{l}\text { API } \\
\text { threat }\end{array}$ & $\begin{array}{c}\text { API } \\
\text { challenge }\end{array}$ & $\begin{array}{c}R Q \\
\text { secure }\end{array}$ & $\begin{array}{c}R Q \\
\text { fearful }\end{array}$ & $\begin{array}{l}\text { RQ pre- } \\
\text { occupied }\end{array}$ & $\begin{array}{c}R Q \\
\text { dismissing }\end{array}$ & $\begin{array}{l}\text { DASS } \\
\text { stress }\end{array}$ & $\begin{array}{l}\text { DASS } \\
\text { anxiety }\end{array}$ & $\begin{array}{c}\text { DASS } \\
\text { depression }\end{array}$ & $\begin{array}{c}\text { ASQ } \\
\text { comfort }\end{array}$ & $\begin{array}{c}\text { ASQ } \\
\text { anxiety }\end{array}$ \\
\hline API threat & $0.36^{* * *}$ & $0.65^{\star * *}$ & 1 & & & & & & & & & & \\
\hline$R Q$ secure & -0.03 & -0.11 & -0.15 & 0.07 & 1 & & & & & & & & \\
\hline$R Q$ fearful & 0.14 & $0.17^{*}$ & 0.13 & -0.02 & $-0.19^{*}$ & 1 & & & & & & & \\
\hline $\mathrm{RQ}$ preoccupied & 0.10 & $0.20^{*}$ & 0.13 & 0.09 & 0.04 & $0.37^{\star * *}$ & 1 & & & & & & \\
\hline DASS anxiety & $0.36^{* \star *}$ & $0.50^{\star * *}$ & $0.47^{\star * *}$ & -0.15 & -0.15 & 0.15 & 0.15 & 0.10 & $0.79^{* \star *}$ & 1 & & & \\
\hline DASS depression & $0.38^{* * *}$ & $0.59^{* * *}$ & $0.61^{* * *}$ & $-0.20^{*}$ & $-0.23^{\star *}$ & $0.17^{*}$ & 0.06 & 0.07 & $0.74^{* * *}$ & $0.71^{* * *}$ & 1 & & \\
\hline ASQ comfort & -0.08 & -0.14 & -0.11 & $0.31^{* * *}$ & $0.43^{* * *}$ & $-0.27^{\star *}$ & -0.14 & 0.042 & -0.15 & $-0.22^{*}$ & $-0.29^{* *}$ & 1 & \\
\hline ASQ anxiety & 0.01 & $0.41^{* * *}$ & $0.38^{* * *}$ & 0.04 & $-0.38^{* * *}$ & $0.36^{* * *}$ & $0.50^{\star \star *}$ & 0.035 & $0.33^{\star * *}$ & $0.36^{* * *}$ & $0.43^{\star \star \star}$ & $-0.42^{* * *}$ & 1 \\
\hline Oswestry disability & $0.43^{* * *}$ & $0.27^{* *}$ & $0.39^{* * *}$ & -0.17 & 0.05 & -0.08 & 0.02 & -0.08 & $0.34^{\star * *}$ & $0.32^{* *}$ & $0.32^{* * *}$ & 0.13 & 0.14 \\
\hline
\end{tabular}

***Significant to 0.000; **Significant to 0.005; *Significant to 0.05. API Average pain intensity; ASQ Attachment style questionnaire; DASS Depression anxiety stress scales; PAI Pain appraisal inventory; RQ Relationship questionnaire

TABLE 4

Mean of the relationship questionnaire (RQ) categorical attachment variables

\begin{tabular}{|c|c|c|c|c|}
\hline \multirow[b]{2}{*}{ Variable } & \multicolumn{4}{|c|}{ RQ Attachment } \\
\hline & $\begin{array}{l}\text { Secure } \\
\text { mean }(n)\end{array}$ & $\begin{array}{l}\text { Fearful } \\
\text { mean }(n)\end{array}$ & $\begin{array}{l}\text { Preoccupied } \\
\text { mean }(n)\end{array}$ & $\begin{array}{c}\text { Dismissing } \\
\text { mean }(n)\end{array}$ \\
\hline Threat & $3.71(47)^{\star}$ & $4.36(27)^{*}$ & $4.13(15)$ & $4.31(31)^{*}$ \\
\hline Challenge & $2.82(47)$ & $2.97(27)$ & $3.37(15)$ & $2.88(32)$ \\
\hline ASQ comfort & $45.35(48)^{*}$ & $35.63(27)^{*}$ & 39.64 (14) & $39.13(32)^{*}$ \\
\hline ASQ anxiety & $54.58(48)^{*}$ & $80.5(24)^{*}$ & $87.17(12)^{*}$ & $69.45(29)^{*}$ \\
\hline Catastrophizing & $11.9(47)$ & $16.7(27)$ & $16.8(15)$ & $16.4(31)$ \\
\hline Anxiety & $7.13(46)^{\star}$ & $13.7(25)^{*}$ & $11.2(15)$ & $15.6(31)^{*}$ \\
\hline Depression & $11.66(47)^{*}$ & $21.41(27)^{*}$ & $15.47(15)$ & $18.39(31)$ \\
\hline Stress & $14.91(46)^{*}$ & $20.42(24)$ & $21.86(14)$ & $22.52(31)^{*}$ \\
\hline
\end{tabular}

*Denotes significant difference. ASQ Attachment style questionnaire

variables were catastrophizing and the three scales of the DASS (stress, anxiety and depression). All four of these analyses yielded significant results. Although categorical RQ was significantly related to catastrophizing $(\mathrm{F}[3,116]=2.9, \mathrm{P}=0.04)$, a post hoc Bonferroni test was unable to distinguish between the four attachment groups. However, inspection of the mean values suggested that secure individuals catastrophized less than those in the fearful, preoccupied and dismissing categories (Table 4).

ANOVA between categorical RQ and DASS anxiety revealed a significant result $(\mathrm{F}[3,113]=5.372, \mathrm{P}=0.002)$, and a post hoc Bonferroni test indicated that secure individuals reported less anxiety than fearful $(\mathrm{P}=0.046)$ and dismissing $(\mathrm{P}=0.002)$ individuals (Table 4). RQ was also related to DASS depression $(\mathrm{F}[3,116]=5.13, \mathrm{P}=0.002)$, and post hoc testing revealed that secure attachment significantly differed from fearful attachment $(\mathrm{P}=0.002)$ and dismissing attachment $(\mathrm{P}=0.055)$. Finally, attachment style was related to DASS stress $(\mathrm{F}[3,111]=3.64, \mathrm{P}=0.015)$, with secure individuals reporting less stress than dismissing individuals $(\mathrm{P}=0.02)$ (Table 4)
Refocus on attachment and appraisal variables: Mediated effects

In line with hypotheses suggesting that cognitive appraisals may mediate the associations between attachment and other pain-related variables, several of the links already established warrant further attention. Baron and Kenny (61) have described four criteria that must be met for a variable to be considered to operate as a mediator: the independent variable must be significantly related to the mediator; the mediator must be significantly related to the dependent variable; the independent variable must be significantly related to the dependent variable; and the inclusion of the dependent variable in the equation must significantly reduce the relationship between the independent and dependent variables. Five sets of variables met the first three of these criteria. These were tested for mediation as described below.

Catastrophizing: The possibility that threat appraisal mediates the relationship between ASQ anxiety and catastrophizing was explored. When ASQ anxiety and threat appraisal were both used to predict threat appraisal, a significant result was obtained $(\mathrm{F}[2,118]=52.23, \mathrm{P}<0.001)$, accounting for $46.1 \%$ of the variance in catastrophizing. Threat appraisal accounted for most of this association $(\mathrm{B}=0.59, \mathrm{t}=8.19, \mathrm{P}<0.001)$, and the contribution of ASQ anxiety was considerably decreased relative to the univariate regression analyses (from $\mathrm{B}=0.41$, $\mathrm{t}=4.91, \mathrm{P}<0.001$ to $\mathrm{B}=0.18, \mathrm{t}=2.53, \mathrm{P}=0.013)$. A Sobel $z$-test was conducted to test for the significance of the indirect effect of attachment on catastrophizing via threat appraisal (61). This analysis revealed partial mediation $(z=8.18, \mathrm{P}<0.001)$, indicating that threat appraisal partially mediated the relationship between ASQ anxiety and catastrophizing.

Depression: ASQ anxiety, threat and depression were all significantly correlated. Threat and ASQ anxiety together predicted depression $(\mathrm{F}[2,117]=34.52, \mathrm{P}<0.001)$, with threat demonstrating a slightly stronger relationship with depression $(B=0.46, t=5.85, P<0.001)$. The relationship between ASQ anxiety and threat $(B=0.25, t=3.2, P=0.002)$ in this equation was somewhat smaller than that determined in univariate regression $(\mathrm{B}=0.43, \mathrm{t}=5.22, \mathrm{P}<0.001)$. A Sobel $z$-test confirmed partial mediation $(z=3.58, \mathrm{P}<0.001)$. Thus, threat 
appraisal also partially mediated the relationship between ASQ anxiety and depression.

In a similar vein, ASQ comfort and challenge appraisal were significantly correlated, and each was negatively correlated with DASS depression. ASQ comfort and challenge appraisal together predicted depression $(\mathrm{F}[2,130]=6.9, \mathrm{P}=0.001)$, and comfort was more strongly negatively related to depression $(\mathrm{B}=-0.37, \mathrm{t}=-2.85, \mathrm{P}=0.005)$ than was challenge appraisal. Nevertheless, the addition of challenge to the regression equation decreased the relationship between ASQ comfort and depression (from $\mathrm{B}=-0.294, \mathrm{t}=-3.54, \mathrm{P}=0.001$ to $\mathrm{B}=-0.25$, $\mathrm{t}=-2.81, \mathrm{P}=0.005)$. The Sobel $z$-test did not reach significance $(z=-1.36, P=0.18)$. Thus, it appears that challenge appraisal did not mediate the association between ASQ comfort with relationships and DASS depression.

Anxiety: When the significant correlations between ASQ anxiety, threat and DASS anxiety were considered, a similar pattern was found. Together, ASQ anxiety and threat appraisal explained $25.2 \%$ of the variance in DASS anxiety $(\mathrm{F}[2,115]=20.67, \mathrm{P}<0.001)$. Threat appraisal was most strongly related to DASS anxiety $(\mathrm{B}=0.4, \mathrm{t}=4.59, \mathrm{P}<0.001)$. The inclusion of threat in the regression equation decreased the association between ASQ anxiety and DASS anxiety (from $\mathrm{B}=0.36$, $\mathrm{t}=4.16, \mathrm{P}<0.001$ to $\mathrm{B}=0.213, \mathrm{t}=2.49, \mathrm{P}=0.015$ ); however, the Sobel $z$-test was not significant $(z=1.92, \mathrm{P}=0.055)$. Thus, threat appraisal did not mediate the relationship between ASQ and DASS anxiety.

Stress: Correlations between threat, ASQ anxiety and DASS stress were also significant. When threat and ASQ anxiety were entered together to predict DASS stress, a significant result was obtained $(\mathrm{F}[2,115]=19.91, \mathrm{P}<0.001)$, accounting for $24.4 \%$ of the variance in stress. Threat appraisal was most strongly related to stress $(\mathrm{B}=0.42, \mathrm{t}=4.84, \mathrm{P}<0.001)$. The inclusion of threat in the equation decreased (to borderline significance) the association between ASQ anxiety and DASS stress (from $\mathrm{B}=0.33, \mathrm{t}=3.71, \mathrm{P}<0.001$ to $\mathrm{B}=0.17, \mathrm{t}=1.91$, $\mathrm{P}=0.059)$. A Sobel $z$-test confirmed full mediation $(z=4.84$, $\mathrm{P}<0.001)$. Hence, threat mediated the relationship between ASQ anxiety and DASS stress.

\section{DISCUSSION}

A preliminary aspect of the present study was the exploration of the use of the PAI in a chronic pain population. As predicted, factor analysis confirmed the presence of two factors consistent with those detected in the acute and experimental samples, and, therefore, these factors were labelled threat and challenge. Also as expected, both reliability coefficients indicated that the scales were adequate for use with the present sample. This finding suggests that the PAI was a statistically sound tool to use in the study.

Individuals with chronic pain in the present study appraised their pain as more threatening and more challenging compared with the acute pain sample reported by Unruh and Ritchie (12). This observation is consistent with findings by McCracken (62), who showed that repeated failed attempts to control pain result in an increased perception of threat, and with findings by Unruh and Ritchie (12), who showed that threat appraisal increased with duration of pain. Such a finding is particularly relevant given the role of appraisal in the selection and activation of coping approaches (30), as well as in further activation of the attachment system (8). Appraisal of an event as personally relevant and threatening, and of the self as possessing inadequate coping resources, leads to problematic adjustment. Attachment theory emphasizes that perceptions of self, the range of available coping resources and strategies, and ability to cope will be compromised for those with insecure patterns of attachment $(6,21,23)$. Thus, in the face of a perceived threat, the attachment filter and associated attachment behaviours warrant attention as a therapeutic priority.

\section{Attachment and appraisal variables in the context of chronic pain}

A further goal of the present research was to investigate the associations between adult attachment and pain appraisal. It was proposed that secure attachment would be associated with greater challenge appraisal, while anxious attachment would be related to heightened threat perceptions. Further, it was theorized that the level of attachment security would have implications for the individual's experience of distress, catastrophizing, pain intensity and disability, and that appraisal variables would impact on this relationship. Overall, findings of this study provide considerable support for the main hypotheses, and are discussed below in more detail.

Threat appraisal: Consistent with our hypotheses, threat appraisal was strongly linked to attachment anxiety. High relationship anxiety was associated with increased perceptions of pain as threatening, and individuals identifying themselves as securely attached were less likely to appraise their pain negatively. An unexpected finding was that fearful and dismissing (avoidant) individuals were more likely to appraise their pain as threatening. This finding suggests that, while avoidant individuals may prefer to minimize and deny their distress, they may be unable to rely on these strategies in chronic pain. The failure of preoccupied attachment to be significantly related to threat appraisal was surprising, but may be related to a lack of power (only 15 participants reported preoccupied attachment relative to 27 fearful and 31 dismissing individuals).

Consistent with findings by Unruh and colleagues $(12,13)$, appraisal of threat was further associated with increased depression, anxiety and stress. Such links between appraisal and emotion are consistent with findings by Jones et al (43), and support their contention that assessment and treatment of those with chronic pain should include a focus on emotional, as well as cognitive and behavioural, strategies. This suggestion is also consistent with attachment theory, which emphasizes the communicative nature of emotion and conceptualizes the internal working model as comprising attachment-related emotions and cognitions (14).

Strong univariate links between catastrophizing, threat appraisal and attachment anxiety are consistent with literature linking catastrophizing separately to threat appraisal (13) and attachment anxiety (4). Further, the multivariate finding that catastrophizing was the strongest single predictor of threat appraisal was not unexpected. Interestingly, threat appraisal provided only partial mediation between attachment anxiety and catastrophizing, suggesting that anxiety over relationships retains a significant link with catastrophizing beyond the effect of threat appraisal. Taken together, these results support the argument for a conceptual link between attachment security and the cognitive appraisal of pain, and further support the conceptualization of catastrophizing as an attachment behaviour.

In addition, threat appraisal was shown to fully mediate the relationship between attachment anxiety and stress, and to partially mediate the relationship between attachment anxiety 
and depression. However, threat appraisal did not mediate between attachment anxiety and general anxiety. These results vary from that predicted by cognitive theory (ie, that cognition precedes emotion), and emphasize the importance of considering both attachment and emotion in the therapeutic arena. Significant links between threat appraisal and both pain intensity and disability are consistent with findings by Unruh and Ritchie (12).

Challenge appraisal: As predicted, strong links were identified between attachment comfort and challenge appraisal, and between attachment security and challenge appraisal. Of the other variables, only depression had any relationship with challenge appraisal, such that those who did not perceive their pain as a challenge were more depressed. However, the relationship between attachment comfort and depression was not mediated by challenge appraisal. Overall, these findings support a more primary role of emotion in relation to attachment than that suggested by cognitive theory, and is further evidence of the primacy of emotions in the chronic pain population. This finding highlights the protective nature of secure attachment, and the value of considering the attachment construct in relation to pain treatment approaches.

\section{Attachment and other variables}

Profiles of attachment variables are presented below, considering categories and dimensions of attachment separately. In terms of the categorical measure, secure individuals were higher in comfort and challenge appraisal, and lower in depression, catastrophizing, anxiety and stress compared with the insecure (particularly fearful and dismissing) individuals. Those reporting a preoccupied attachment style were highest in attachment anxiety, but tended to be lower than the other insecure styles in threat, catastrophizing, anxiety, depression and stress. Interestingly, the preoccupied group was higher than the other insecure categories (albeit marginally) in the resilience-related variables of attachment comfort and challenge appraisal. Thus, despite their high relationship anxiety, these individuals presented in less distress than fearful and dismissing participants.

As expected, the fearful style was low on comfort with relationships, and high on perceptions of threat, anxious attachment, anxiety and depression. The dismissing group reported the highest levels of stress, and was also high on threat appraisal, relationship anxiety and general anxiety. This result is interesting because, as noted earlier, this subgroup usually prefers to minimize and deny stress. Perhaps dismissing individuals are more willing to acknowledge emotional distress when it is caused by something as concrete as physical pain. Alternatively, the finding may relate to a reduction in the capacity for this group to effectively use previous self-regulatory mechanisms, such as excess work focus and activity, when in pain (2).

In terms of dimensional measures, those high on comfort with closeness were less anxious and less depressed, while those high on anxiety over relationships were more stressed, depressed, anxious and catastrophized. These findings are consistent with findings from other clinical and community samples, and extend the currently limited data available in the pain population.

The opportunity also exists to heed the call of Mikail et al (3) to investigate the representation of each of the various attachment categories within the chronic pain population. Only
$33.3 \%$ of the present sample reported a secure attachment style, which is $20 \%$ to $40 \%$ lower than frequencies reported in other studies (63-65). The extent of fearful, preoccupied and dismissing attachment styles was greater in the study, although the distribution among insecure attachment styles did not differ consistently from other studies that report dismissing as the largest insecure group, and preoccupied as the smallest. While sampling bias might explain the present findings, it seems likely securely attached individuals, with more adaptive affective and coping strategies, may be more likely to volunteer to participate in research requiring completion of additional questionnaires. Hence, the secure attachment category may indeed be over represented in this study, and a less voluntary sample may report even smaller rates of secure attachment.

Pain intensity and disability are notably absent from these profiles. While the failure of attachment variables to be significantly related to pain intensity or disability may seem surprising, it is conceptually consistent with the attachment and coping literature $(30,42)$. Attachment patterns (or dispositions) indicate relatively stable personality, emotional and social characteristics that form the background against which appraisals are made and coping responses engaged. Chapman et al (66) determined that it was the level of sympathetic nervous system arousal that determined the accuracy of a pain report, while Kohn et al (67) demonstrated that high arousal was linked with higher pain intensity ratings. Thus, at any point in time, it might be expected that the physiological state associated with current emotions and cognitions would be a better predictor of pain intensity and disability than would be the disposition underlying that state.

\section{Implications}

Overall, the findings of the present study have implications for present treatment approaches. An attachment perspective, addressing cognitive, behavioural and emotional issues, offers a useful metaperspective (68) for treatment of the clinical pain population. Unlike personality dispositions underlying chronic pain conditions, which have been viewed as refractory to treatment (42), adult attachment patterns are seen as amenable to therapeutic intervention. Both long-term and short-term interventions have been described, including 'secure priming' (69-72) and relationship-based psychotherapy approaches $(72-74)$. Results of the study suggest that exploration of these approaches for those with chronic pain should be a priority.

One of the departures of the attachment perspective compared with the present cognitive approach to pain is the interpretation of cognitive processes as over-learned responses, rather than conscious decisions. Tomaka et al (33) noted that cognitive appraisal is a dynamic process in which reappraisals alter the perception of threat or challenge. While there is no doubt that threat or challenge appraisals can be consciously manipulated, attachment theory holds that a trend to perceive events as threatening or challenging would vary from one individual to the next as a function of attachment security. Indeed, results of the present study highlight the importance of considering the role of catastrophizing (proposed as an attachment behaviour) and emotions. Filtering an event through internal working models that automatically interpret increased threat and perceive the self as having few resources to cope, with consequences for emotional, physiological and behavioural responses, presupposes problematic adjustment. The opportunity exists to assist pain sufferers in identifying 
this filter, and to design treatment programs to suit various attachment needs.

\section{Strengths and limitations}

A number of limitations of the present study need to be considered. The use of voluntary participants introduces the dilemma of selection bias. However, confidentiality considerations precluded the possibility of exploring differences between those who agreed to participate and those who did not. Further, while the present study used self-report measures with demonstrated validity and reliability, reliance on self-reports may be considered a weakness. Future research in this field might consider supplementing these measures with more objective measures, including observation, standardized assessment and perceptions of significant others. It is worth noting, however, that Jensen et al (75) found that patients' self-reported beliefs about their pain behaviours and functioning were significantly associated with those of both spouses and independent observers.

Because of evidence of associations between attachment anxiety and neuroticism (76), it may have been valuable to have incorporated neuroticism as a covariate in the present study. While neuroticism may be included in future analyses in this area, it is equally important to note that the relationship between neuroticism and attachment anxiety is modest, and evidence suggests that these are not redundant constructs (76). Indeed, neuroticism has proven less powerful than attachment measures in predicting either romantic relationship variables (76) or the tendency to engage in cosmetic procedures (77). Specifically, Davis and Vernon (77) noted that, unlike neuroticism, those with high attachment anxiety are concerned about obtaining and maintaining the approval of others.

\section{REFERENCES}

1. Kolb LC. Attachment behavior and pain complaints. Psychosomatics 1982;23:413-25

2. Anderson DJ, Hines RH. Attachment and pain. In: Grzesiak RC, Ciccone DS, eds. Psychosocial Vulnerability to Chronic Pain. New York: Springer-Verlag, 1994:137-52.

3. Mikail SF, Henderson PR, Tasca GA. An interpersonally based model of chronic pain: An application of attachment theory. Clin Psychol Rev 1994;14:1-16.

4. Ciechanowski P, Sullivan M, Jensen M, Romano J, Summers H. The relationship of attachment style to depression, catastrophizing and health care utilization in patients with chronic pain. Pain 2003; 104:627-37.

5. McWilliams LA, Cox BJ, Enns MW. Impact of adult attachment styles on pain and disability associated with arthritis in a nationally representative sample. Clin J Pain 2000;16:360-4.

6. Mikulincer M, Florian V. The relationship between adult attachment styles and emotional and cognitive reactions to stressful events. In: Simpson JA, Rholes WS, eds. Attachment Theory and Close Relationships. New York: Guilford Press, 1998:143-65.

7. Pearce S, Creed P, Cramond T. Attachment style and chronic pain syndrome. Aust Pain Soc Newsletter 2001:2-4

8. Bartholomew K, Cobb RJ, Poole JA. Adult attachment patterns and social support processes. In: Pierce GR, Lakey B, Sarason IG, Sarason BR, eds. Sourcebook of Social Support and Personality. New York: Plenum Press, 1997:359-77.

9. Butler D, Moseley L. Explain Pain. Adelaide: Noigroup Publications, 2003.

10. Sanford SD, Kersh BC, Thorn BE, Rich MA, Ward LC. Psychosocial mediators of sex differences in pain responsivity. J Pain 2002;3:58-64.

11. Unruh AM. Gender variations in clinical pain experience. Pain 1996;65:123-67.
An important strength of the present paper is that it explored a large group of people in real-life distress, at a point of seeking intervention from a tertiary treatment facility. While this recruitment approach makes it likely that attachment models will be activated, it does limit the generalizability of the findings. Further, data in the present study are cross-sectional and, therefore, causality is difficult to address. It would be valuable to consider these questions at the end of such a treatment program, as well as to consider those in the community with chronic pain and subgroups of individuals with homogenous diagnoses. In addition, it is important to address the longitudinal implications of attachment and threat appraisals of pain.

\section{CONCLUSION}

Results support the theorized links between pain appraisal and adult attachment security, and reinforce findings of previous studies linking attachment security and pain appraisals separately with catastrophizing and emotional distress. Further, this study highlights the primacy of attachment and emotional variables in the pain experience, emphasizing the need for these to be addressed in treatment. Results suggest that both attachment theory and pain appraisal offer useful insights to the chronic pain experience, warranting further exploration in terms of assessment and treatment.

ACKNOWLEDGEMENTS: The authors acknowledge the generous support of the staff and clients of both Gregory Terrace Rehabilitation and PainLogic during the data collection process. The statistical advice of Dr Ross Darnell is also appreciated. This research was made possible by a joint scholarship from the Graduate School Postgraduate Research Studies Unit and the School of Health and Rehabilitation Sciences at The University of Queensland, Australia.
12. Unruh AM, Ritchie J. Development of the pain appraisal inventory: Psychometric properties. Pain Res Manage 1998;3:105-10.

13. Unruh AM, Ritchie J, Merskey H. Does gender affect appraisal of pain and pain coping strategies? Clin J Pain 1999;15:31-40.

14. Bowlby J. Attachment, vol 1. New York: Basic Books, 1969.

15. Bowlby J. A Secure Base: Parent-Child Attachment and Healthy Human Development. New York: Basic Books, 1988.

16. Mikulincer M. Attachment styles and the mental representation of the self. J Pers Soc Psychol 1995;69:1203-15.

17. Bartholomew K. Avoidance of intimacy: An attachment perspective. J Soc Pers Relat 1990;7:147-78.

18. Bartholomew K, Horowitz LM. Attachment styles among young adults: A test of a four-category model. J Pers Soc Psychol 1991;61:226-44.

19. Feeney JA, Noller P, Hanrahan M. Assessing adult attachment In: Sperling MB, Berman WH, eds. Attachment in Adults: Clinical and Developmental Perspectives. New York: Guilford, 1994:128-52

20. Fraley RC, Waller NG. Adult attachment patterns: A test of the typological model. In: Simpson JA, Rholes WS, eds. Attachment Theory and Close Relationships. New York: Guilford Press, 1998:77-114.

21. Torquati JC, Vazsonyi AT. Attachment as an organizational construct for affect, appraisals, and coping of late adolescent females. J Youth Adol 1999;28:545-62.

22. Cole-Detke H, Kobak R. Attachment processes in eating disorder and depression. J Consult Clin Psychol 1996;64:282-90.

23. Alexander R, Feeney J, Hohaus L, Noller P. Attachment style and coping resources as predictors of coping strategies in the transition to parenthood. Pers Rel 2001;8:137-52.

24. Jensen MP, Turner JA, Romano JM, Karoly P. Coping with chronic pain: A critical review of the literature. Pain 1991;47:249-83. 
25. Nicassio PM, Schoenfeld-Smith K, Radojevic V, Schuman C. Pain coping mechanisms in fibromyalgia: Relationship to pain and functional outcomes. J Rheumatol 1995;22:1552-8.

26. Raak R, Wikblad K, Raak A Sr, Carlsson M, Wahren LK. Catastrophizing and health-related quality of life: A 6-year follow-up of patients with chronic low back pain. Rehabil Nurs 2002;27:110-6.

27. Turner JA, Jensen MP, Romano JM. Do beliefs, coping, and catastrophizing independently predict functioning in patients with chronic pain? Pain 2000;85:115-25.

28. Burns JW, Kubilus A, Bruehl S, Harden RN, Lofland K. Do changes in cognitive factors influence outcome following multidisciplinary treatment for chronic pain? A cross-lagged panel analysis. J Consult Clin Psychol 2003;71:81-91.

29. Lazarus RS. Coping theory and research: Past, present, and future. Psychosom Med 1993;55:234-47.

30. Lazarus RS, Folkman S. Stress, Appraisal, and Coping. New York: Springer, 1984.

31. Lazarus RS, Kanner AD, Folkman S. Emotions: A cognitivephenomenological analysis. In: Plutchik R, Kellerman H, eds. Emotion: Theory, Research, and Experience. Vol 1: Theories of emotion. New York: Academic Press, 1980:189-217.

32. Tomaka J, Blascovich J. Effects of justice beliefs on cognitive appraisal of and subjective, physiological, and behavioral responses to potential stress. J Pers Soc Psychol 1994;67:732-40.

33. Tomaka J, Blascovich J, Kelsey RM, Leitten CL. Subjective, physiological, and behavioral effects of threat and challenge appraisal. J Pers Soc Psychol 1993;65:248-60.

34. Feeney BC, Kirkpatrick LA. Effects of adult attachment and presence of romantic partners on physiological responses to stress. J Pers Soc Psychol 1996;70:255-70.

35. Feeney JA, Ryan SM. Attachment style and affect regulation: Relationships with health behavior and family experiences of illness in a student sample. Health Psychol 1994;13:334-45.

36. Hunter JJ, Maunder RG. Using attachment theory to understand illness behavior. Gen Hosp Psychiatry 2002;23:177-82.

37. Simpson JA, Rholes WS. Stress and secure base relationships in adulthood. Adv Person Rel 1994;5:181-204.

38. Feeney JA. Adult attachment, coping style and health locus of control as predictors of health behaviour. Aust J Psychol 1995;47:171-7.

39. Schmidt S, Strauss B, Braehler E. Subjective physical complaints and hypochondriacal features from an attachment theoretical perspective. Psychol Psychother 2002;75:313-32.

40. Keefe FJ, Lefebvre JC, Smith SJ. Catastrophizing research: Avoiding conceptual errors and maintaining a balanced perspective. Pain Forum 1999;8:176-80.

41. Keefe FJ, Kashikar-Zuck JC, Robinson E, et al. Pain coping strategies that predict patients' and spouses' ratings of patients' self-efficacy. Pain 1997;73:191-9.

42. Geisser ME. The influence of coping styles and personality traits on pain. In: Dworkin RH, Breitbart WS, eds. Psychosocial Aspects of Pain: A Handbook for Health Care Providers. Progress in Pain Research and Management, vol 27. Seattle: IASP Press, 2004:521-45.

43. Jones DA, Rollman GB, While KP, Hill ML, Brooke RI. The relationship between cognitive appraisal, affect, and catastrophizing in patients with chronic pain. J Pain 2003;4:267-77.

44. Sullivan MJ, Thorn B, Haythornthwaite JA, et al. Theoretical perspectives on the relation between catastrophizing and pain. Clin J Pain 2001;17:52-64.

45. Fairbank JC, Couper J, Davies JB, O'Brien JP. The Oswestry low back pain questionnaire. Physiotherapy 1980;66:271-3.

46. Fairbank JC, Pynsent PB. The Oswestry disability index. Spine 2000;25:2940-52

47. Roland M, Fairbank J. The Roland-Morris disability questionnaire and the Oswestry disability questionnaire. Spine 2000;25:3115-24 (Erratum in 2001;26:847).

48. Turk DC, Melzack R, eds. Handbook of Pain Assessment, 2nd edn. New York: Guilford Press, 2001.

49. Carlsson AM. Assessment of chronic pain. I. Aspects of the reliability and validity of the visual analogue scale. Pain 1983;16:87-101.

50. Jensen MP, Karoly P, Braver S. The measurement of clinical pain intensity: A comparison of six methods. Pain 1986;27:117-26.
51. Lovibond PF, Lovibond SH. Manual for the Depression Anxiety Stress Scales (DASS). Sydney: Psychology Foundation, 1993.

52. Lovibond PF, Lovibond SH. The structure of negative emotional states: Comparison of the depression anxiety stress scales (DASS) with the Beck depression and anxiety inventories. Behav Res Ther 1995;33:335-43.

53. Crawford JR, Henry JD. The depression anxiety stress scales (DASS) Normative data and latent structure in a large non-clinical sample. Br J Clin Psychol 2003;42:111-31.

54. Brown TA, Chorpita BE, Korotitsch W, Barlow DH. Psychometric properties of the depression anxiety stress scales (DASS) in clinical samples. Behav Res Ther 1997;35:79-89.

55. Clara IP, Cox BJ, Enns MW. Confirmatory factor analysis of the depression anxiety stress scales in depressed and anxious patients. J Psychopath Behav Assess 2001;23:61-7.

56. Scharfe E, Bartholomew K. Reliability and stability of adult attachment patterns. Pers Relat 1994;1:23-43.

57. Herzberg DS, Hammen C, Burge D, Daley SE, Davila J, Lindberg N. Attachment cognitions predict perceived and enacted social support during late adolescence. J Adol Res 1999;14:387-404.

58. Strahan BJ. Predictors of depression: An attachment theoretical approach. J Fam Stud 1995;1:33-47.

59. Stein H, Koontz AD, Fonagy P, et al. Adult attachment: What are the underlying dimensions? Psychol Psychother 2002;75:77-91.

60. Rosenstiel AK, Keefe FJ. The use of coping strategies in chronic low back pain patients: Relationship to patient characteristics and current adjustment. Pain 1983;17:33-44

61. Baron RM, Kenny DA. The moderator-mediator variable distinction in social psychological research: Conceptual, strategic, and statistical considerations. J Pers Soc Psychol 1986;51:1173-82.

62. McCracken LM. Learning to live with the pain: Acceptance of pain predicts adjustment in persons with chronic pain. Pain 1998;74:21-7.

63. Klohnen EC, John OP. Working models of attachment: A theory-based prototype approach. In: Simpson JA, Rholes WS, eds. Attachment Theory and Close Relationships. New York: Guilford Press, 1998:115-40.

64. Mickelson KD, Kessler RC, Shaver PR. Adult attachment in a nationally representative sample. J Pers Soc Psychol 1997;73:1092-106.

65. Roney A, Meredith PJ, Strong J. Attachment styles and factors affecting career choice of occupational therapy students. Br J Occ Ther 2004;67:133-41

66. Chapman CR, Donaldson GW, Nakamura Y, Jacobson RC, Bradshaw DH, Gavrin J. A psychophysiological causal model of pain report validity. J Pain 2002;3:143-55.

67. Kohn PM, Cowles MP, Dzinas K. Arousability, need for approval, and situational context as factors in pain tolerance. J Res Pers 1989;23:214-24.

68. Lopez FG. Attachment theory as an integrative framework for family counseling. Fam J 1995;3:11-7.

69. Mikulincer M. Adult attachment style and affect regulation: Strategic variations in self-appraisals. J Pers Soc Psychol 1998;75:420-35.

70. Mikulincer M, Arad D. Attachment working models and cognitive openness in close relationships: A test of chronic and temporary accessibility effects. J Pers Soc Psychol 1999;77:710-25.

71. Mikulincer M, Shaver PR. Attachment theory and intergroup bias: Evidence that priming the secure base schema attenuates negative reactions to out-groups. J Pers Soc Psychol 2001;81:97-115.

72. Sonkin D, Dutton D. Treating assaultive men from an attachment perspective. J Aggress Maltreat Trauma 2003;7:105-33.

73. Goodwin I. The relevance of attachment theory to the philosophy, organization, and practice of adult mental health care. Clin Psychol Rev 2003;23:35-56.

74. Dallos R. Attachment narrative therapy: Integrating ideas from narrative and attachment theory in systemic family therapy with eating disorders. J Fam Ther 2004;26:40-65.

75. Jensen MP, Romano JM, Turner JA, Good AB, Wald LH. Patient beliefs predict patient functioning: Further support for a cognitive behavioural model of chronic pain. Pain 1999;81:95-104.

76. Shaver PR, Brennan KA. Attachment styles and the 'big five' personality traits: Their connections with each other and with romantic relationship outcomes. Society Pers Soc Psychol 1992;18:536-45.

77. Davis D, Vernon ML. Sculpting the body beautiful: Attachment style, neuroticism, and use of cosmetic surgeries. Sex Roles 2002:47:129-38. 


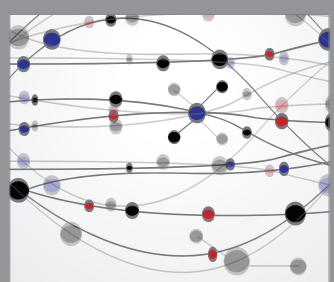

The Scientific World Journal
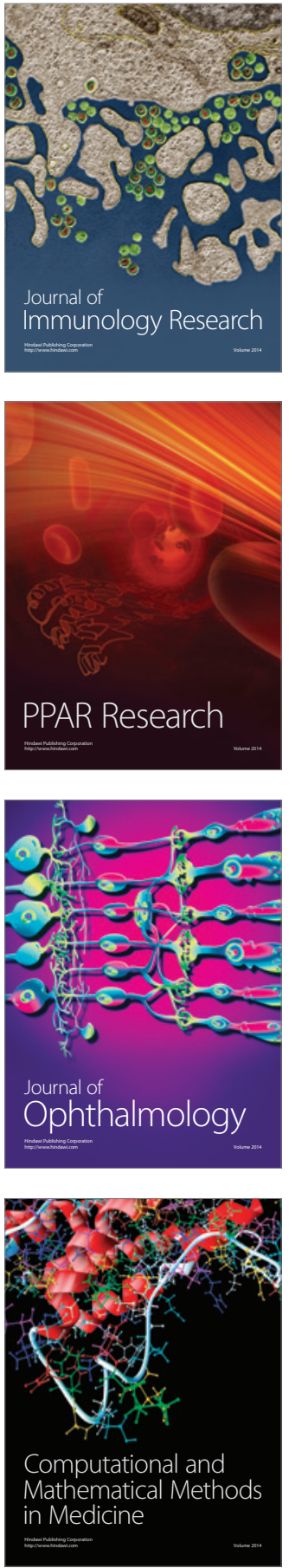

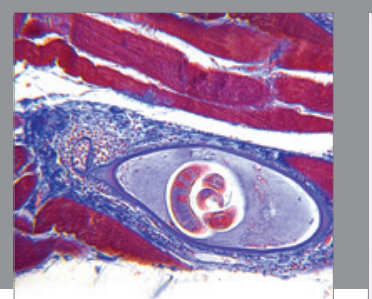

Gastroenterology Research and Practice

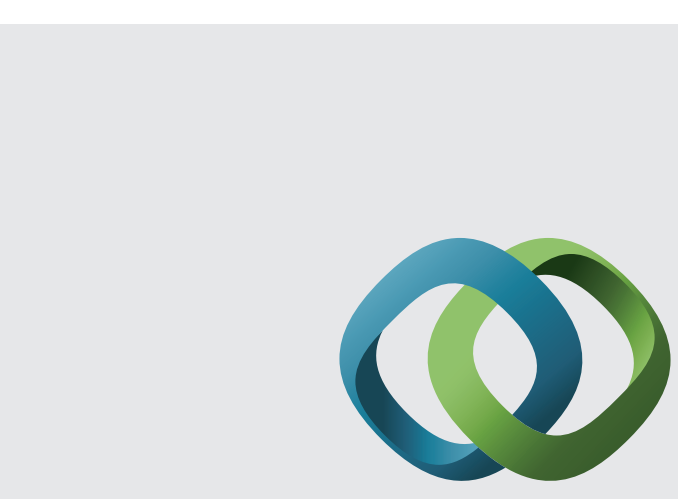

\section{Hindawi}

Submit your manuscripts at

http://www.hindawi.com
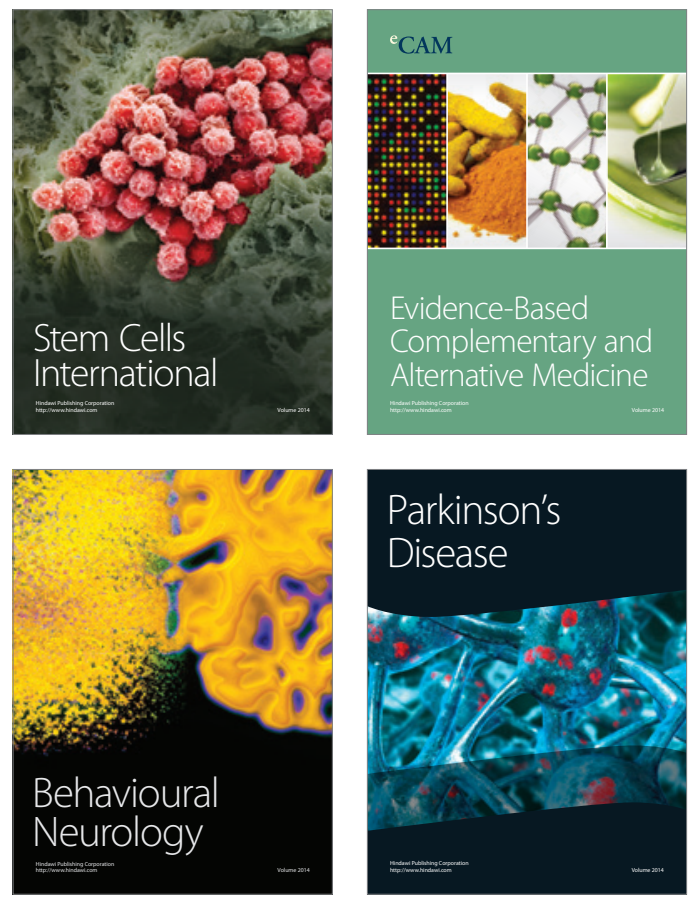
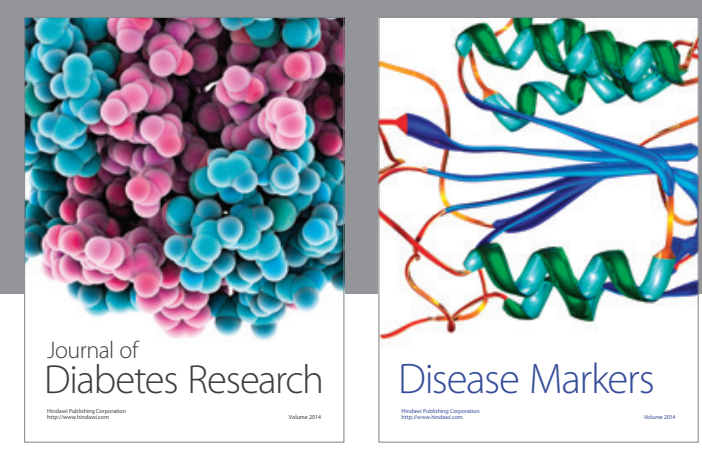

Disease Markers
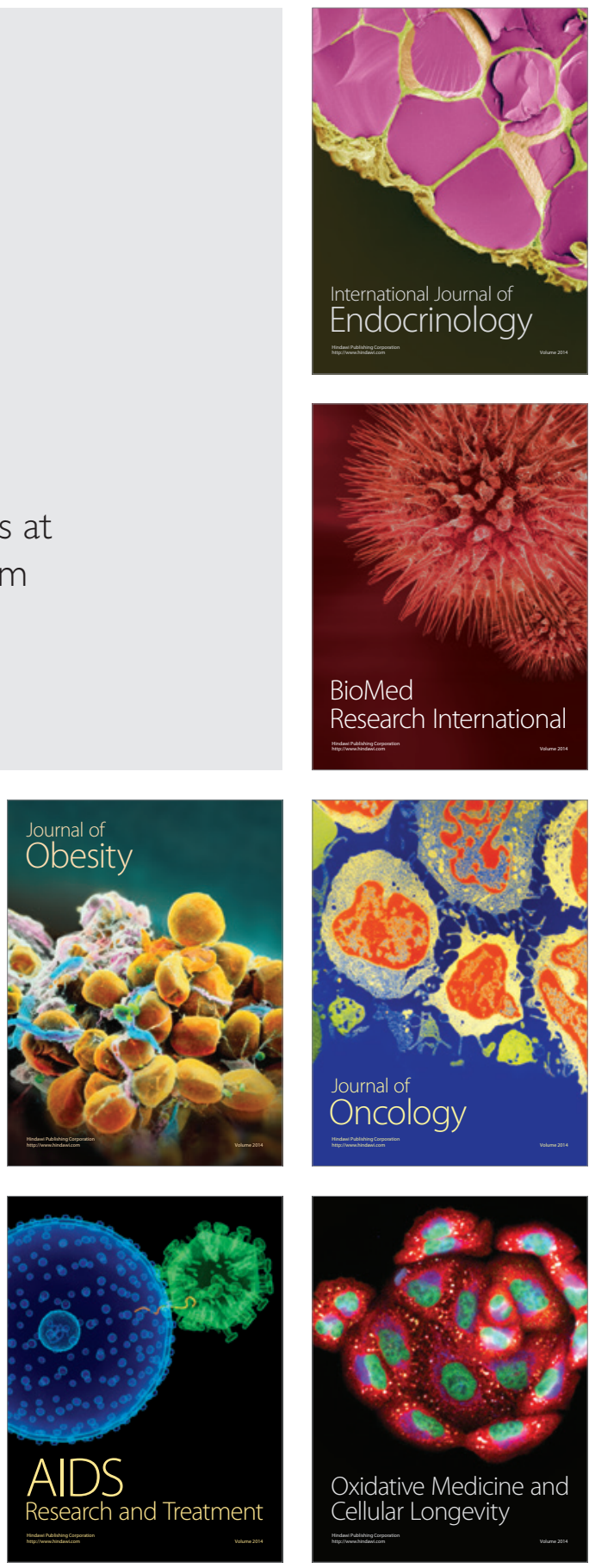